\title{
Collaborative Research: A Synergistic Approach to Socio-Economic Development
}

\author{
A. A. Orunsolu, \\ Department of Computer \\ Science and Engineering, \\ Moshood Abiola Polytechnic, \\ Ojere, Abeokuta, Nigeria
}

orunsoluabdul@yahoo.com

\author{
O. R. Vincent \\ Department of Computer \\ Science, University of \\ Agriculture, \\ Abeokuta, Nigeria \\ rv@tu-clauthal.de
}

\section{A. A. Adebayo and O. O. Bamgboye \\ Department of Computer Science and Engineering, Moshood Abiola Polytechnic, Ojere, Abeokuta, Nigeria}

debamos04@yahoo.com; seunbamgboye2000@yahoo.com

\begin{abstract}
Collaborative research, which is any research project in which at least two experts pool their resources together, has several benefits to the socio-economic development of any progressive society. Good collaborative research has to be well planned so that the expertise involved in the project can be optimally utilized through clear role definitions. In this work, we present the people-process-product (3P) paradigm as it relates to collaborative research in addressing the socioeconomic development in a society. The $3 \mathrm{P}$ approach clearly specifies the roles of individual researchers in the overall development of collaborative research. The stages in this approach can be used to evaluate the effectiveness of collaborative research in national development.
\end{abstract}

Keywords: Collaborative Research, Knowledge Management, Socio-Economy, Information Technology and Development.

\section{Introduction}

Socio-economics is the study of the relationship between economic activity and social life. It is a multidisciplinary field that uses theories and methods which cut across sociology, economics, history, psychology, and many others. It has emerged as a separate field of study in the late twentieth century (Alan, 2005). In many cases, socio-economists focus on the social impact of some

Material published as part of this publication, either on-line or in print, is copyrighted by the Informing Science Institute. Permission to make digital or paper copy of part or all of these works for personal or classroom use is granted without fee provided that the copies are not made or distributed for profit or commercial advantage AND that copies 1) bear this notice in full and 2) give the full citation on the first page. It is permissible to abstract these works so long as credit is given. To copy in all other cases or to republish or to post on a server or to redistribute to lists requires specific permission and payment of a fee. Contact Publisher@InformingScience.org to request redistribution permission. sort of economic change. Such changes might include a closing factory, market manipulation, the signing of international trade treaties, new natural gas regulation, etc. Such social effects can be wide-ranging in size, anywhere from local effects on a small community to changes to an entire society.

Socio-economic development can be likened to a process of social and eco- 
nomic development in a society. The development is measured with indicators, such as expectancy, literacy and levels of employment. Changes in less-tangible factors are also considered, such as personal dignity, freedom of association, personal safety and freedom from fear of physical harm, and the extent of participation in civil society. Socio-economic impact may be caused by new technologies, changes in laws, changes in the physical environment and ecological changes such as prolonged drought or declining fish stocks. These may affect patterns of consumption, the forced distribution of incomes and wealth, the way in which people behave, and the overall quality of life. Economic development is therefore, the increase in the standard of living of a nation's population with sustained growth from a simple, low-income economy to a modern, high-income economy (Boateng \& Heeks, 2008). Its scope includes the process and policies by which a nation improves the economic, political, and social well-being of its people.

Social development is a process, which results in the transformation of social structures in a manner that improves the capacity of the society to fulfill its aspirations (Dabla, 2004). The process of subconscious element of society emerged as conscious knowledge is pioneered by individuals. Social change comprises four well- marked stages- survival, growth, development and evolution, each of which contains elements of the other three within it. Development is therefore a qualitative change in the way society carries its activities, such as through more progressive attitudes and behavior by the population, research by educationist, the adoption of more effective social organizations or more advanced technology, which may have been developed elsewhere through a collaborative research effort.

Collaborative research refers to the process in which researchers, intended users, and relevant stakeholders work together to define the research problem or issue; design the appropriate research approach; interpret results and implications; and disseminate research results to the appropriate individuals and organizations (Zittoun et. al., 2007). It is any research project that is carried out by at least two people. Collaborative research occurs in many ways, and is more common in some fields than others (Kogevinas et al, 2004). It is very common in the sciences, and less so in the humanities. Working with others on a research project can have several benefits, but there can be drawbacks as well. Researchers may choose to collaborate when a project is large in order to combine their strengths in the different areas of the proposed project. When done in the right spirit, collaborative research can result in more reliable and powerful results.

In this paper, we propose to use the 3P approach to collaborative research as a tool for national development. This approach is adopted from works of Khan on e-learning technology. From this viewpoint, we present in section 2 the collaboration research model. Section 3 focuses on the 3P and its socio-economic implications. Some concluding remarks are given in section 4 .

\section{Collaborative Research Models}

Collaborative research models focus on ways in which collaborative research works and how to understand research better. These models make collaborative research easier and simple to manage. For this work, two collaborative models are discussed below:

\section{(a) Consensus Building Model}

Consensus Building is a process of seeking unanimous agreement that involves a good-faith effort to meet the interests of all stakeholders. The main structure of a consensus building approach is Joint Fact Finding (JFF), which has six steps, all of which occur collaboratively with researchers, intended users, and relevant stakeholders. The steps are as follows:

(i) Prepare to convene a JFF effort, e.g., understand how JFF fits into the process and document interests of stakeholders. 
(ii) Scope the problem, i.e., generate technical questions, existing knowledge, and gaps in knowledge.

(iii) Define data collection/analysis methods and assess costs and benefits of different approaches.

(iv) Conduct the research.

(v) Evaluate results, e.g., compare findings to literature and translate findings into policy responses.

(vi) Communicate research results.

(b) Collaborative Learning

Collaborative learning model is appropriate for natural resource, environmental, and community decision-making situations that have the following characteristics: multiple parties, deeply held values, cultural differences, multiple issues, scientific and technical uncertainty, and legal and jurisdictional constraints. It emphasizes activities that encourage systems thinking, joint learning, open communication, constructive conflict management, and a focus on appropriate change (Khan, 2005).

\section{The 3P Paradigm to Collaborative Research}

The People-Process-Product (3P) continuum model is be used to map a comprehensive picture of collaborative research as described in Khan (2005). The collaborative research process can be divided into two major phases: (1) research content development, and (2) research content delivery and maintenance. A typical collaborative research process has planning, design, development, evaluation, delivery, and maintenance stages (Luukkonen et al., 1993). The collaborative research process is iterative in nature. Although evaluation is a separate stage of the collaborative research process, ongoing formative evaluation for improvement should always be embedded within each stage of the collaborative research process. Individuals involved in various stages of the collaborative research process should be in contact with each other on a regular basis and revise materials whenever needed (Khan, 2004).

Based on the size and scope of the project, the number of individuals involved in various stages of collaborative research project may vary. Some roles and responsibilities may overlap, as many collaborative research tasks are interrelated and interdependent (Beaver, 2001). A large-sized collaborative research project requires the involvement of various individuals. In a small or mediumsized collaborative research project, some individuals will be able to perform multiple roles. When a collaborative research course is completely designed, developed, taught, and managed by a single individual, it is clear that the same individual has performed the role of content expert, instructional designer, programmer, graphic artist, project manager, etc (Cowan \& Jonard, 2003). 


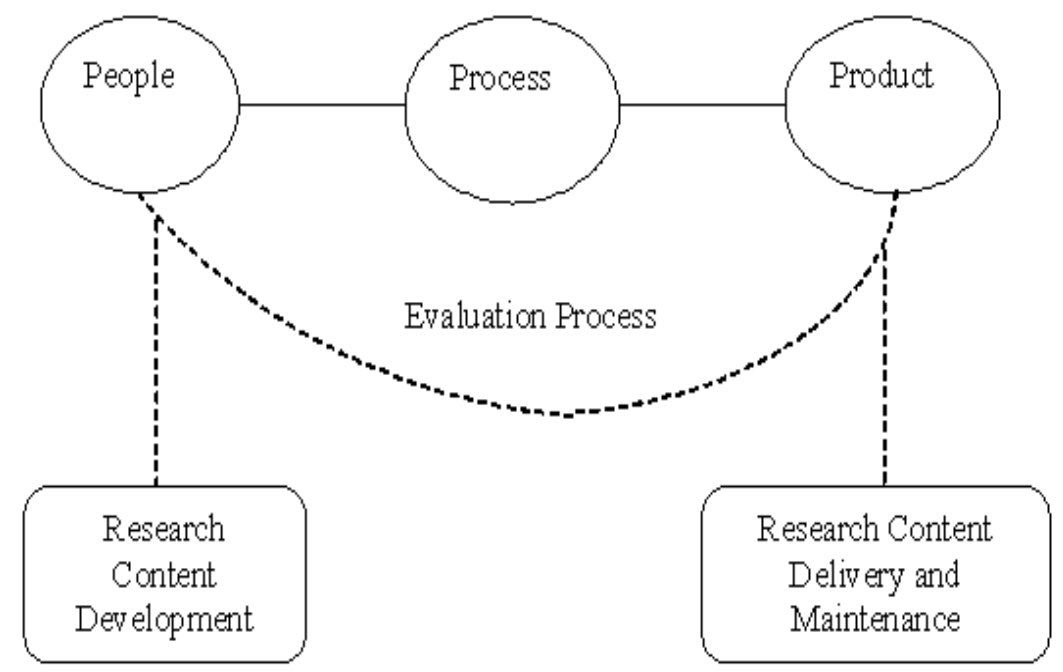

Figure 1: The 3P Model

\section{Method of 3P Collaboration}

The 3P collaboration is designed to develop a process or product design that meets customer requirements best economic manner. The steps in the $3 \mathrm{P}$ event used in this work are described below.

(i) Define Product or Process Design: The group seeks to understand the principal customer needs that must be met. If a product or product prototype is available, the project group breaks it down into component parts and raw materials to assess the function that each plays (Glanzel and Schubert, 2005).

(ii) Diagramming: A diagram or other type of illustration is created to demonstrate the flow from raw material to finish product. The project team then analyzes each branch of the diagram (or each illustration) and brainstorms key words to describe the change made at each branch.

(iii) Find and Analyze Natural examples: The project team then tries to find examples of each process keyword in the natural world. Similar examples are grouped together and examples that best simplify the process keyword are taken for better understanding on how its best fit the topic in consideration. Once the unique qualities of the natural process are dissected, team members then discuss how the natural process can be applied to the given manufacturing process step (Glanzel, 2001).

(iv) Sketch and Evaluate the Process: Sub-teams are formed and each sub-team member is required to draw different ways to accomplish the process in question. Each of the sketches is evaluated and the best is chosen along with any good features from the sketches that are not chosen for a mock-up.

(ii) Build, Present, and Select Process Prototypes: The team prototypes and then evaluates the chosen process, spending several days (if necessary) working with different variations of the mock-up to ensure it will meet criteria.

(vi) Hold Design Review: Once a concept has been selected for additional refinement, it is presented to a larger group (including the original product designers) for feedback. 
(vii) Develop Project Implementation plan: If the project is selected to proceed, the team selects a project implementation leader who helps determine the schedule, process, resource requirements, and distribution of responsibilities for completion.

\section{A 3P Collaborative Research Framework}

The people-process-product paradigm is a three-phase cycle that consists of the input (people), action (process) and results (product). The cycle begins with the series of planning initiated by research team (see Figure 2). There is usually a principal investigator (PI) that controls all the resources and specifies roles of individual researchers. The people provide the input which could be in form of experience in certain problem solving areas, technical skills, roles of each partner in the collaboration, research scope, how changes in the research will be made and feedback of results.

The input provides direction for carrying out the research which can assist the research team when evaluating the results and contribution of individual researchers. The input also extends to planning where the research team develops a project by identifying the various parameters such as finance, training and supervision, formal agreement and compliance needed to achieve the scope of research. The finance depicts the expenses incurred in the course of carrying out the research work such as equipments or hardware to be purchased and data gathering cost. The training and supervision addresses the facts that the partner in the collaborative research may not have the same expertise level which could result in the need for proper coordination and effective contribution from all the researchers in the team. The formal agreement addresses the facts that research project may not be domicile in one place and it may be necessary to transfer research materials from one place to another. Formal agreement takes care of the ownership and protection of research materials in the events of moving from one place to another. Compliance indicates that collaborative research should satisfy specific research rules and regulations, which could vary from one location to another. The compliance may also indicate how to seek for funds and some other technical areas of collaborative research.

The data gathering exercise is another component of the input (people) stage. The data-gathering phase is used to establish facts needed to justify the workability of research in terms of cost/benefits analysis. Collaborative researches that satisfy the relation in equation (1) are likely to create opportunities that will promote the socio-economic development.

$$
\text { Input }+ \text { process }<\text { product }
$$

The second stage is the process phase where inputs from researchers are translated into actions. A process is a collection of interrelated work tasks initiated in response to an event that achieves a specific result for the customer of the process. Developing a good process in a collaborative research implies that all the input parameters should be available in the right format and right quantities. For example, if one of the member of the research, team decides to abandon his roles and specification then there is no way to achieve a good process unless someone takes up the challenge. A collaborative research process has two characteristics: predicable and sequential. Predictable implies that regardless of the initial conditions and execution details of a research project every possible outcome should be easily anticipated. The predictability of the process stage not only determines the success and failure conditions, but also determines the possibility for process loops and recalibration. This implies that there is a research member usually the principal investigator (PI), who understands the risks of each activity and who is prepared to undergo those risks during execution and initiate the appropriate action. Overlooking the consequences of sequential ability of a process can significantly reduce the likelihood of process success. First, the order of the activities within the process must be known. Secondly, there must be criteria for starting an activity. Additionally, there must be criteria for recognizing the completion of an activity. These 
all imply that there is someone usually the PI, responsible for activities, how they relate, and how to measure the criteria so that process control decisions can be made correctly.

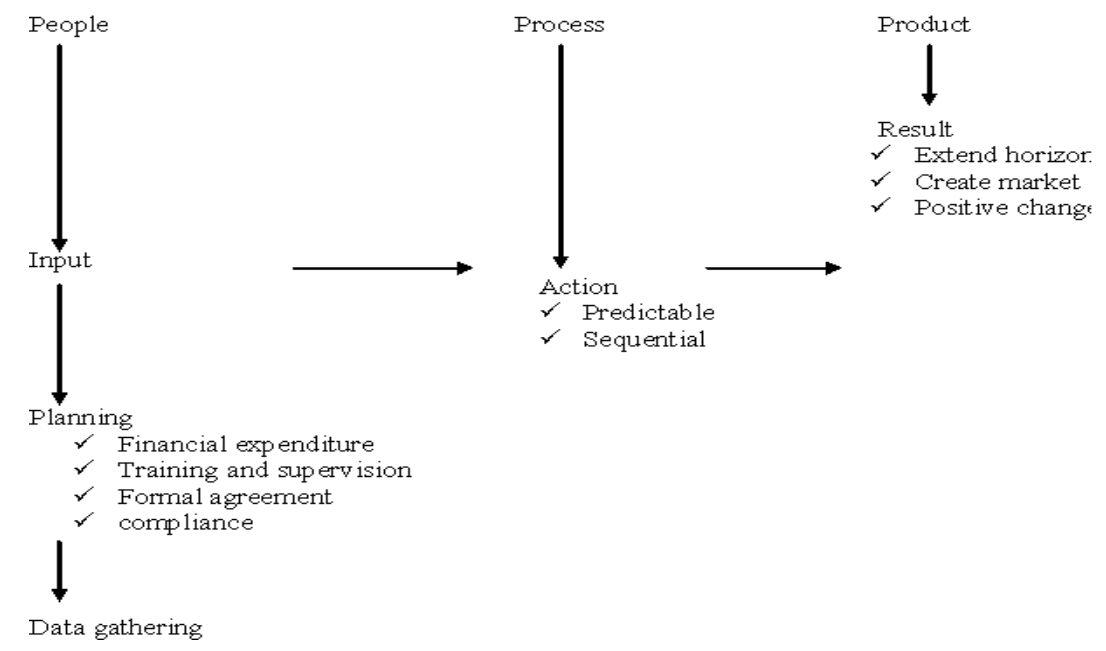

Figure 2: The 3P collaborative research data flow diagram

The result phase deals with the translation of process into products. This product could be in forms of services, goods or technological innovation generated from the collaborative efforts. The success of research products in greater extents determines the success of a collaborative research. A good research product should naturally create market for socio-economic development. The scope of this marketing operation may depend on institutions' collaborative research policies and types of their clients (Wagner et al., 2005). Other factors that determine the success and evaluation of a good research product includes but not limited to:

- Positive changes in behavior of intended beneficiary

- Economic significance of research results

- Extension of knowledge into other areas

- Level of growth of research team after completing the project

\section{Effect of 3P Approach on Socio-Economic Development}

The $3 \mathrm{P}$ approach has a great significance on the socio-economic development of any organizations or countries in which it is adopted as a collaborative research approach. This approach stresses the fact that the final destination of any research is the market value (Khan, 2004). If efforts of collaborative research are market-oriented, then any Country can create jobs through research efforts. The implication is that such research may create a new culture and attitude in the mind of young researchers who will see beyond "publication-crazy syndrome" to research efforts. Market-oriented collaborative research through 3P will equally attracts grants for effective research necessary for socio-economic development.

\section{Advantages of Collaborative Research to Socio-Economic Development}

Some advantages of collaborative research are discussed below:

(i) Better access to expertise, equipment and resources: This advantage may be pivotal for interdisciplinary research and to what extent it is in fact realized remains to be investigated. An important related aspect is to what extent there is transfer of know-how from one country to another, 
thus contributing to the development of expertise and research capabilities in countries which lack a specific experience. A systematic evaluation of past collaborative research will illustrate these aspects. Though, it seems sometimes difficult to establish effective communication between groups working in different disciplines, the scientists who belong and work in one discipline can easily use familiar terminology to communicate.

(ii) Better access to funds: Collaborative research creates access to national as well as international project funding.

(iii) More prestige and visibility:

(iv) Better efficiency and productivity: Collaboration gives more value to the study, though it involves more bureaucratic procedures.

(v) Taking advantage of the varied environmental conditions: In environmental epidemiology, one of the most important assets of collaborative research is taking advantage of the large variability in environmental conditions across the World. This is an area where working on principles to guide collaborations and to ensure the mutual benefit of all the involved groups is of outstanding importance.

Other benefits of collaborative research include increase in the level of funding available for research by the government of cooperate organisation. Collaboration also enhances greater understanding by research users through the building of direct relationships between researchers and founders, an increase in the direct contact between the researcher and the sponsors, leading to greater understanding and cementing of relationship for future research collaborations. All these benefits have direct relationships with socio-economic development of any society. The funds attracted by collaborative research efforts can have wide economic and social implications on any society and institutions. Countries with good record of accomplishment of research success have more appeals for researchers and other international founders of landmark research programmes.

\section{Conclusions}

In this paper, the people-process-product paradigm was presented as a tool for synergistic requirement for using collaborative research. The people provide the input for developing collaborative research through proper planning, identification of roles and scope and data gathering activities. The process is the action phase where inputs are translated into results. The product is the final output, which determines the success and the significance of socio-economic impacts of collaborative research. The integration of $3 \mathrm{P}$ approach with knowledge management can be used to improve the knowledge retention capacity of a collaborative research in a socio-economic development.

It is not to be expected that collaborative research will progress spontaneously to the desired directions. Specific policies will encourage and orientate collaborations. Within this context, it may also be considered to change the ways is which scientists are evaluated: shifting from the predominance of using quantity to more qualitative criteria and finding ways for their meaningful implementation. Particular ways to increase the efficiency and interaction in interdisciplinary and intercultural collaboration may be developed. It is obvious that these may be the areas that do not directly contribute to the economic growth but indirectly these are the areas, which will help in eradicating poverty, creating and accessing economic opportunities and the same time sustainability and adaptation, which is the key for success in the economy. 


\section{References}

Beaver, D. (2001). Reflections on scientific collaboration (and its study): Past, present and future. Scientometrics, 52, 365-377.

Boateng, R., Heeks, R., Molla, A., \& Hinson, R. (2008). E-commerce and socio-economic development: Conceptualizing the link. Journal of Internet Research, 18(5), 562-594.

Cowan, R., \& Jonard, N. (2003). The dynamics of collective invention. Journal of Economic Behavior and Organization, 52, 513-532.

Dabla, A. (2004). The role of IT Policies in promoting social and economic development: The case of the state of Andhra Pardesh, India. EJISDC, 19(5), 1-21.

Deardorff, A. (n.d.) Economic development. Deardorff's Glossary of international economics. Retreived from http://www-personal.umich.edu/ alandear/glossary/

Glanzel, W. (2001). National characteristics in international scientific co-authorship relations. Scientometrics, 51, 69-115.

Glanzel, W. (2003). Bibliometrics as a research field. A course on theory and applications of bibliometric indicators.

Glanzel, W., \& Schubert, A. (2005). Domesticity and internationality in co-authorship, references and citations. Scientometrics, 65, 323-342.

Khan, B. H. (2004, September-October). People, process and product continuum in e-learning: The elearning P3 model. Educational Technology,.44(5), 33-40.

Khan, B. H. (2005). Managing e-learning: Design, delivery, implementation, and evaluation. Hershey, PA: Information Science Publishing.

Klea, K. (2008). Collaborative research: Accomplishments and potential. Environmental Health, 7(3). doi:10.1186/1476-069X-7-3.

Kogevinas, M., Nybo Andersen A., \& Olsen, J. (2004). Collaboration is needed to co-ordinate European birth cohort studies. International Journal of Epidemiology, 33, 1172-1173.

Luukkonen, T., Tijssen, R. J. W., Persson, O., \& Sivertsen, G. (1993). The measurement of international scientific collaboration. Scientometrics, 28, 15-36.

Zittoun, T., Baucal, A., Cornish, F., \& Gillespie, A. (2007). Collaborative research, knowledge and emergence. Integrative Psychological and Behavioral Science, 41, 208-217.

Tongia, R., Subrahmanian, E., \& Arunachalam, V. (2005). Information and communication technology for sustainable development. Defining a global research agenda. Bangalore, p.13.

Wagner, C., Cave, J., Tesch, T., Allee, V., Thompson, R., Leydesdorff, L., \& Botterman, M. (2005). Evaluation on NETworks of collaboration among participants in IST research and their evolution to collaborations in the European Research Area (ERA). Retrieved from http://ec.europa.eu/\%20dgs/\%20information_society $/ \% 20$ evaluation $/ \% 20$ data/ $\% 20$ pdf $/ \% 20$ studies $/ \% 2$ 02003 01/\%202005_eranets_final.pdf 

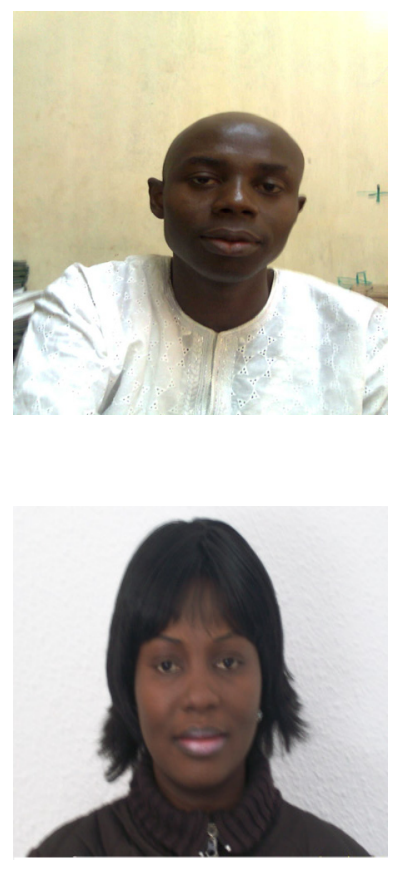

tional and local Journals.
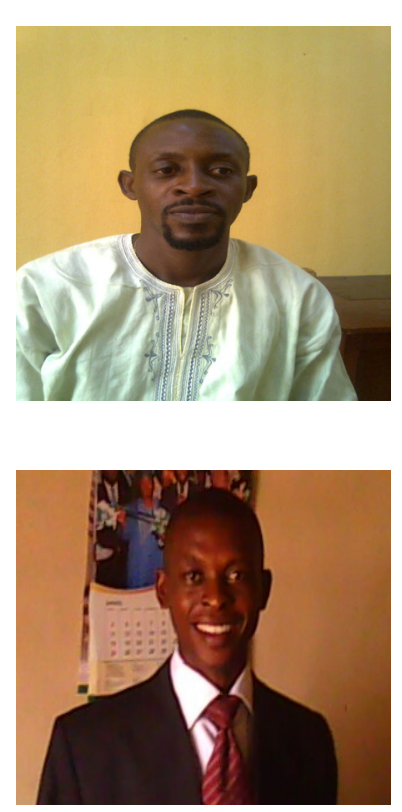

Rebecca Vincent is a Lecturer in the Department of Computer Science, University of Agriculture, Abeokuta. She obtained a B.Sc degree in Mathematical Sciences (Computer Science Option) and M.Sc in Computer Science from the University of Agriculture, Abeokuta in 2000 and 2005 respectively. She is currently rounding up her Ph.D research on Mobile Agents for E-Commerce. Her research interest include: Images and Vision, Knowledge Management, Computational Complexity, E-commerce, Agents and Mobile Agents. She is a member of Nigeria Computer Society and has published in notable Interna-

A. A. Adebayo obtained a Bachelor of Technology in Computer Science (2003) from University of Technology, Akure, Nigeria. He is currently an M.Sc research student at the University of Agriculture, Abeokuta and a lecturer at the Department of Computer Science Moshood Abiola Polytechnic, Abeokuta, Nigeria. His areas of research include Network Management, Image processing Systems, Computer Security and Distributed Database Systems.

O. O. Bamgboye graduated in Mathematical Sciences with Option in Computer Science from University of Agriculture, Abeokuta in 2005. He holds a professional certification in Oracle 10g Database Administration and he is currently pursuing his Masters Degree in Computer Science at the Same Institution. He teaches Computer Science at the Moshood Abiola Polytechnic, Nigeria. His current research interest concern distributed databases system, Knowledge Management Systems, Software Engineering and Artificial Intelligence. 